\title{
Ser oficial combatente do Exército: uma delegação transgeracional?'
}

\author{
Being a combat officer in the Army: \\ a transgenerational delegation?
}

\author{
Silvana de Fátima Lima MOLINA² \\ Cristina Maria de Souza Brito DIAS
}

\begin{abstract}
Resumo
Esta pesquisa teve como objetivo geral investigar a influência exercida pelo pai, oficial do exército, na decisão do filho para seguir a carreira militar e como este último percebe a referida carreira. Especificamente, procurou-se analisar as motivações que levaram à escolha pela carreira por parte dos filhos; os ganhos obtidos e as dificuldades para exercer a carreira; o papel da família e as expectativas acerca do futuro. A pesquisa foi realizada com 20 cadetes alunos da Academia Militar das Agulhas Negras, que responderam a uma entrevista analisada de acordo com a técnica da análise de conteúdo temática. Os resultados apontaram a forte influência do pai, o apoio da família, além da convivência diária com a rotina e as normas da instituição como as principais motivações para a escolha da carreira. O sentimento de orgulho e de honra perpassara todas as entrevistas, embora os participantes tenham reconhecido ser uma carreira caracterizada por perdas, sacrifícios e esforço constante. As expectativas de futuro remetem ao desejo de contínua dedicação para melhorar o desempenho e as colocações, bem como a construção de uma família.
\end{abstract}

Unitermos: Abordagem transgeracional. Família militar. Paternidade.

\begin{abstract}
The aim of this study was to investigate the influence exerted by a father and Army officer, in deciding if the child will follow a military career and how the child perceives this career. More specifically, it sought to analyze the motivations that led to this decision; the gains achieved and the difficulties in exercising this career; the role of the family and expectations for the future. The study was carried out on twenty student cadets in the Agulhas Negras Military Academy (named for one of the highest mountains in Brazil, literally Black Needles). They responded to an interview that was analyzed in accordance with the technique of Thematic Content Analysis. As the main motivations for this career choice, the results pointed to the strong influence of the father, family support, as well as daily contact with the routine and the rules of the institution. The feeling of pride and honor pervaded all the interviews, although they acknowledged that it is a career that involves loss, sacrifice and constant effort. Expectations of the future relate to the desire for continuous dedication to improving the performance and postings, as well as building a family.
\end{abstract}

Uniterms: Transgenerational approach. Military family. Fatherhood.

\section{$\boldsymbol{\nabla} \boldsymbol{\nabla} \boldsymbol{\nabla} \boldsymbol{\nabla}$}

1 Artigo elaborado a partir da dissertação de S.F.L. MOLINA, intitulada "Ter um filho oficial do Exército: uma delegação transgeracional?" Universidade Católica de Pernambuco, 2007.

2 Universidade Federal de Pernambuco. Recife, PE, Brasil.

3 Universidade Católica de Pernambuco, Centro de Teologia e Ciências Humanas, Departamento de Psicologia. R. Do Príncipe, 526, Boa Vista, 50050-900, Recife, PE, Brasil. Correspondência para/Correspondence to: C.M.S.B. DIAS. E-mail: <cristina_britodias@yahoo.com.br>. 
A importância da família na construção da subjetividade da criança tem sido alvo de estudo cada vez mais frequente, especialmente diante da diversidade de transformações que vem ocorrendo na organização familiar. Desse modo, muito tem se falado sobre o papel do pai. Discutem-se as possíveis mudanças no comportamento do homem, tanto no que se refere à construção da identidade masculina quanto ao exercício da paternidade. Fala-se de um "novo pai", capaz de se interessar pelos afazeres do filho, de forma sensível, reconhecendo, inclusive, a importância do vínculo afetivo e aberto para o diálogo. Os pais indiferentes, ausentes, estão dando lugar a pais mais participativos no cuidado dos filhos, embora aqueles que acham que sua obrigação é apenas o sustento da prole continuem a existir. Segundo Jablonski (1999), os conceitos de masculinidade e de paternidade estão em processo de transformação, provocada, principalmente, pelo movimento de emancipação feminina.

De acordo com Prieur (1999, p.19), a humanidade é resultado da "Ionga cadeia de transmissão", que é determinante na construção da identidade do sujeito. Para o autor, o elo entre as gerações é um dos fatores que regem o funcionamento da família e o processo de sucessão faz parte de uma hereditariedade psíquica.

Levando em conta essa hereditariedade psíquica, houve o interesse em pesquisar a família militar: um grupo que não está isento de sofrer as influências das mudanças socioculturais, complexidades e comportamentos que configuram sua dinâmica. Entretanto, é uma família que vive uma experiência ímpar que, em geral, não é experimentada pela família que não tenha o pai militar: separações ocasionadas pelo trabalho do pai (missões de paz, transferências, cursos, missões fora da região); frequentes mudanças; longas horas de trabalho do militar e dedicação exclusiva, principalmente em momentos especiais e de treinamento; controle excessivo quanto a horários e tarefas designadas ao militar (Teachman, Call \& Segal, 1993). O pai, oficial combatente do exército, tradicionalmente, tem seu papel respaldado na concepção de um pai provedor, figura de autoridade e responsável pelo grupo familiar. Sua formação profissional é dirigida para liderar grupos, exercer autoridade e aprender a lidar com hierarquia e disciplina. Desse modo, esse pai traz para sua família reflexos dessa 44 formação, e, na maioria das vezes, reside nas proxi- midades dos quartéis para dedicação exclusiva à carreira. Consequentemente, isso pode influenciar fortemente os projetos profissionais e os valores pessoais de seus membros.

Na experiência da primeira autora como oficial do corpo técnico temporário de Colégio Militar, foi notada a frequência com que os pais dos alunos mostravam-se decepcionados e frustrados quando um dos filhos não desejava seguir a carreira militar. Além disso, foi possível perceber a falta de estimulação, por parte do pai, para que o filho conhecesse outras carreiras. Nota-se também a escassez de estudos sobre essa configuração familiar, especialmente no que tange à escolha da referida carreira.

Com base no que foi exposto, surgiu o interesse em pesquisar a influência exercida pelo pai, oficial do exército, na decisão do filho homem para seguir a carreira militar e como este último percebe a referida carreira. Além disso, procurou-se investigar: as motivações que o levaram à escolha pela referida carreira; os fatores facilitadores e os críticos para exercê-la; o papel da família e as expectativas acerca do futuro.

\section{Transmissão familiar}

Entre as teorias que explicam o funcionamento das famílias, elegeu-se a abordagem transgeracional por ser a que mais se amolda ao conteúdo e aos objetivos da pesquisa. Segundo Falcke e Wagner (2005), o termo transgeracional aponta para o resgate dos elementos que são repetidos e mantidos na família, entre as gerações. Essa perspectiva baseia-se na permanência de representações que constroem a história da família. Dessa forma, em todas as famílias existe uma espécie de herança de atribuições e de papéis, que é repassada ao longo das gerações, influenciando o modo de vida do sujeito e, consequentemente, o processo de subjetivação. A expectativa familiar torna-se o objeto mediador e de forte influência nos sentimentos de pertencer ou se diferenciar do grupo enquanto sujeito. 0 não cumprimento desses papéis herdados poderá causar sentimentos de frustração, de fracasso ou de culpa entre os membros da família.

Bucher-Maluschke (2008, p.77) acrescenta que"o sujeito não é só produto das heranças que ocorrem no interior da família, mas também da que ele recebe na 
esfera social, econômica e cultural, próprias do contexto em que vive". O conjunto dessas heranças contribui para a formação de sua identidade. A autora faz uma distinção entre os teóricos que têm trabalhado as questões transgeracionais na perspectiva sistêmico/psicodinâmica e na psicanalítica.

Neste trabalho, destacam-se alguns conceitos teóricos que se encaixam na primeira perspectiva: 1) lealdade, que "implica a existência de expectativas estruturadas no grupo, em relação às quais todos os membros adquirem um compromisso" (Boszormenyi-Nagy \& Spark, 2003, p.54); 2) delegação, que significa confiar uma missão que "se estende sobre o vínculo da lealdade unindo o "delegante" ao "delegado", e que dá uma direção e uma significação à nossa vida" (Miermont, 1994, p.181); 3) mitos, que "são construções que vão se estabelecendo como verdades ao longo do tempo e que visam a preencher necessidades da família e que exercem um poder muito grande sobre seus membros e até mesmo determinando seu destino" (Falcke \& Wagner, 2005, p. 33); 4) rituais, constituem “uma série de atos e comportamentos codificados pela família e dos quais participam todos ou uma parte de seus membros" (Krom, 2000, p.16).

Krom (2000), ao falar sobre as influências que atravessam as gerações, aponta para as diversas expectativas e projeções que se recebe dos familiares. Refere-se às delegações e aos conteúdos que as novas gerações acolhem, chamando a atenção para a forma determinante que esses fatores têm sobre suas realizações pessoais. Para a referida autora, é importante identificar como são acolhidas essas expectativas e como estão sendo manejados os rituais para a manutenção dos mitos, uma vez que, na maioria das vezes, eles adquirem um "caráter sagrado" e vão permear todas as relações na família. Os mitos têm como uma das funções mais importantes manter a homeostase familiar.

Dessa forma, o processo de delegação funciona como perpetuação de um "legado", que, segundo Falcke e Wagner (2005), tem o objetivo de revelar para as gerações posteriores os valores e as regras que devem continuar na dinâmica familiar. Logo, levanta-se a possibilidade de que ter um filho oficial combatente do exército torna-se uma "delegação" muitas vezes transmitida do avô militar para o pai militar e do pai militar para o filho militar, indicando uma representação narcísica e, por isso, provocadora de identificação. Ou, ainda, trata-se de uma expectativa familiar herdada entre as gerações, que influencia de maneira poderosa as decisões pessoais e, principalmente, o processo de escolha profissional do filho. Krom (2000) também afirma que a escolha de uma profissão é poderosamente influenciada por elementos intergeracionais, e é direcionada por fortes modelos familiares, juntamente com as habilidades e as necessidades de realização pessoal. Geralmente ela vai responder às expectativas tanto individuais quanto familiares.

Na família militar, o pai, na maioria das vezes, mantém-se como disciplinador, alimenta suas fantasias narcísicas ao desejar que o filho o siga na escolha da profissão, assim como repassa o compromisso de ter um membro da família oficial combatente na próxima geração, representado, simbolicamente, pelo ritual de entrega da espada de oficial do exército para o filho, que, muitas vezes, mantém o mesmo "nome de guerra" (nome que oficializa a identidade do militar nas organizações e que fica impresso acima do bolso direito do uniforme que ele utiliza) do pai.

A "Espada de Oficial do Exército", entregue pelo pai oficial combatente (se for o caso, e estando ele na reserva) em solenidade de conclusão do curso do filho, tendo sido usada pelo próprio pai na época de sua formatura e, posteriormente, guardada, é preservada para esse momento. Trata-se de um ritual pelo qual a espada torna-se o símbolo da passagem da herança, do compromisso com a instituição e a sensação de "missão cumprida" no grupo familiar.

\section{A formação militar}

Para Oliveira (2004), o comportamento masculino é fruto de uma série de transformações ocorridas na sociedade, associadas principalmente à origem de algumas instituições, tais como as forças armadas e, especificamente, o exército. Para esse autor, a masculinidade tem sido expressa por meio de símbolos de força e destemor, que foram transferidos para os sentimentos de nacionalismo próprios da formação militar da época moderna.

Dessa forma, quando se observa o Estatuto dos Militares (Brasil, 1980) sobre as profissões militares (independente do posto ou graduação), percebe-se que 
elas envolvem um conjunto de atribuições voltado para a defesa nacional. Em qualquer função ou cargo militar, encontra-se uma diversidade de obrigações que, segundo o Estatuto dos Militares (Brasil, 1980, art. 27), são "manifestações essenciais do valor militar". O oficial formado para ser combatente deve corresponder às exigências previstas neste documento.

O oficial combatente (atualmente previsto exclusivamente para o segmento masculino), segundo a Lei do Ensino do Exército, é um profissional subordinado ao Ministério da Defesa, e, por isso, treinado e preparado para preservar a integridade do Brasil, na paz ou na guerra. O que caracteriza sua habilitação para o combate ou apoio logístico é o seu preparo profissional na Academia Militar das Agulhas Negras (AMAN).

A "sujeição a preceitos rígidos de disciplina e hierarquia" é um dos pilares do funcionamento do exército, onde o dever de cumprir as ordens previstas, mesmo que em desacordo com elas, é condição imprescindível para o militar se adaptar à rotina da caserna. "Ao ingressar nas Forças Armadas, o militar tem de obedecer a severas normas disciplinares e a estritos princípios hierárquicos, que condicionam toda sua vida pessoal e profissional" (Brasil, 1998). Para ilustrar, existe o lema da AMAN: “Cadete! Ides comandar, aprendei a obedecer!". Para ingressar na AMAN, o jovem poderá escolher entre duas alternativas. Uma delas é prestar concurso em âmbito nacional e ser aprovado para Escola Preparatória de Cadetes de Exército (EsPCEx), situada em Campinas (SP), ainda cursando ou tendo concluído a $2^{2}$ série do ensino médio. Deverá ser brasileiro nato, do sexo masculino, e ter entre 15 e 20 anos de idade no ano do concurso. Nessa escola, ele irá cursar disciplinas regulares da $3^{a}$ série do ensino médio, juntamente com as de iniciação militar profissional e receberá o título de "aluno". Outra alternativa é concluir o ensino médio em qualquer escola do País, e prestar o concurso público direto para AMAN, sem frequentar a EsPCEx. Nessa modalidade de ingresso, o jovem deverá seguir os mesmos requisitos para a inscrição na ESPCEx, diferenciando-se apenas na faixa etária.

O jovem que ingressa na EsPCEx e na AMAN vivencia um sistema de internato obrigatório, recebendo durante vinte e quatro horas os princípios militares, durante um período de cinco anos de formação: um 46 ano em Campinas (SP) e quatro na AMAN em Resende
(RJ), sendo afastado da família de origem ainda no período da adolescência. Depois de concluído o curso, o aspirante a oficial (praça especial, assim é classificado na hierarquia militar, após a formatura) deverá estar pronto a ser movimentado, em qualquer época do ano, para as diversas regiões do país, com ou sem estrutura de apoio para sua família. Essas peculiaridades da formação do oficial combatente diferem de outros quadros de oficiais do exército, uma vez que seu ingresso é bastante diferente. Geralmente trata-se de pessoas de idade mais madura, de ambos os sexos e escolaridade superior. O tempo do curso varia entre oito e doze meses e não há exigência ou obrigatoriedade de vivenciar o sistema de internato, como é o caso dos oficiais do centro de Preparação de Oficiais da Reserva (CPOR) ou do quadro técnico na cidade do Recife.

\section{Método}

Trata-se de uma pesquisa qualitativa, que se caracteriza por investigar o fenômeno em sua complexidade, por meio de um contato aprofundado com os indivíduos em seu próprio contexto.

\section{Participantes}

Foram entrevistados 20 cadetes do exército que estavam estudando na AMAN, em Resende (RJ), independente da Arma, Quadro ou Serviço (Infantaria, Artillharia, Cavalaria, Engenharia, Intendência, Material Bélico e Comunicações), ano do curso (Básico, Avançado, $3 \circ$ ou $4^{\circ}$ anos) ou local de origem, uma vez que o concurso é de âmbito nacional. Eles são provenientes de diferentes estados e todos são filhos e netos de militares do exército, com média de idade de 21 anos, solteiros e membros de família nuclear. Inseridos nesse grupo de entrevistados, encontraram-se 10 que têm, além dos pais e avôs, irmãos, tios ou outro parente militar, seja das forças armadas (exército, marinha ou aeronáutica) ou de Forças Auxiliares (Polícia Militar e Corpo de Bombeiros).

Os pais, em sua maioria, já foram para a reserva (aposentadoria). Apenas um serve como instrutor dentro da academia. A escolha dos militares com este perfil - combatente do exército - e com formação nessa escola, foi baseada nas características específicas do quadro de oficiais de carreira, graduados em ciências 
militares. Os participantes foram escolhidos tendo em vista sua disponibilidade, mediante as atividades realizadas no período em que a pesquisadora visitou a AMAN.

\section{Instrumento}

Foi utilizado um roteiro de entrevista, realizada individualmente e conduzida de forma semidirigida, que compreendeu dez questões relacionadas aos objetivos da pesquisa e os dados sociodemográficos dos participantes. O roteiro de entrevista foi elaborado pelas autoras, com base nos objetivos do estudo e compreendeu: as motivações para seguir a carreira militar, os fatores que interferiram na escolha, as dificuldades e os ganhos obtidos, características essenciais do militar, bem como o papel da família e as expectativas diante do futuro. A entrevista é, segundo Minayo (2004, p.107), "a técnica mais utilizada no processo de trabalho de campo". Cada entrevista foi gravada e, posteriormente, transcrita.

\section{Procedimentos}

Realizou-se uma visita à AMAN para preencher dados e apresentar documentos. Posteriormente, por meio de contato telefônico ou via correio eletrônico, agendou-se, com o apoio da Seção Psicopedagógica, o período de coleta, indicado por conta dos jogos escolares e, por isso, sem a necessidade de retirar o cadete da escola de formação. Elaborou-se também uma carta-convite nominal a cada participante, para ser enviada por meio de endereço eletrônico, antes da realização da entrevista, com tempo e espaço previamente organizado pela referida seção.

Ao chegar à AMAN, já havia sido reservada uma sala para a realização das entrevistas, cujo horário já havia sido divulgado pelo Corpo de Cadetes e pela Seção Psicopedagógica. Os cadetes se dirigiram no horário combinado para as entrevistas, e após serem informados dos seus objetivos e esclarecidos acerca do sigilo e resguardo de suas identidades, foi-lhes solicitado que assinassem o termo de consentimento livre e esclarecido. As entrevistas foram feitas individualmente e duraram, em média, 30 minutos. A pesquisa foi aprovada pelo Comitê de Ética da universidade onde foi realizado o estudo sob o n CEP 078/2005.
As entrevistas foram analisadas individualmente com base na técnica de análise de conteúdo temática. Segundo Minayo (2004, p.209), ela"consiste em descobrir os núcleos de sentido que compõem uma comunicação, cuja presença ou frequência signifiquem alguma coisa para o objetivo analítico visado". Dessa forma, tendo por base a literatura consultada, foram analisados seis temas, assim denominados: motivações para seguir carreira militar; dificuldades encontradas; ganhos obtidos com a dedicação à carreira militar; características essenciais do militar; papel da família, e expectativas em relação ao futuro.

\section{Resultados e Discussão}

Os resultados apresentados são referentes aos temas investigados de acordo com os objetivos da pesquisa.

\section{Motivações para seguir a carreira militar}

Todos os entrevistados afirmaram que a influência do pai e demais familiares foi fator decisivo para que desejassem seguir carreira militar. Além disso, a vivência no quartel durante a infância, o conhecimento da carreira e a admiração pelas atividades que o pai desempenhava, assim como o ingresso no colégio militar, foram evidenciados nos relatos dos cadetes. Esses motivos corroboram o que foi observado por Rosa (2006), ao referir, na sua pesquisa com 133 cadetes filhos de militares, que o pai e o fato de estudar em colégio militar influenciaram sua escolha pela carreira.

Meu avô émilitar, meu tio e meu paitambém. Ele dizque vivia dentro de um quartel e também fez o colégio militar, como eu. A influência da família vaidirecionando (cadete no 1).

Bem, meu avô é militar, dois tios também e meu pai é sargento. Crescidentro da rotina militar. Fuipara o colégio militar e pensei "se gostar eu fico" e fui ficando. Foi de tudo um pouquinho (risos) (cadete no 2).

Meu avôfalava muito que ser militaréuma boa profissão, meu pai vibra com a carreira militar e toda criança adora ver um soldado, não é? Eu cheguei a pensar em ser advogado, diplomata, mas gosto muito de farda, formatura, essas coisas (cadete no 3).

Nessa temática, a decisão para ser militar foi fundamentada na relação construída com o pai, e até 
mesmo com o avô, e no significado que eles têm para a família. Para Andolfi e Ângelo (1988), a forma como se expressa o relacionamento entre pai e filho contém, implicitamente, informações sobre como um pai percebe hoje a relação existente entre ele e seu próprio pai. Como refere Corneau (1997, p.27), há uma "presença psicológica" no cotidiano do filho e na construção de sua identidade. O pai, além de ser"figura de autoridade, princípio moral", como pontua Costa (1994, p.95), expressa afetividade e interesse, na medida em que se torna referência e participa ativamente da vida do filho.

Ele (pai) sempresanou minhas dúvidas. Toda dúvida que eu tinha a respeito da carreira eu procurava primeiro ele. Eu admiro muito ele, porque ele tá sempre dando força... (cadete $n^{\circ} 7$ ).

Quando você tem um pai, no caso, militar, sempre tá te falando sobre como é aquilo, com certeza influencia bastante, te dá ali pelo menos uma noção e te dá mais um reforço para você decidir nesta escolha. Acho que facilita. (cadete no 12).

As afirmações correspondem ao que referem Andolfi e Ângelo (1988, p. 37) quanto ao"código comportamental" e explicam como as imagens são incorporadas como modelo de conduta. O pai é representante de sucesso, força e bravura e, por isso, pode funcionar como diretriz de vida para o cadete. Pode-se supor ainda que a satisfação auferida pelos pais com sua própria carreira é repassada para os filhos através dos conselhos e orientações, contribuindo para a autoestima de todos. Para Cia e Barbam (2008), a satisfação obtida nas atividades pessoais está diretamente relacionada ao desempenho no ambiente familiar. Confirmando esse pensamento, encontrou-se que os cadetes filhos de militares, investigados na pesquisa de Rosa (2006), referiram mais satisfação com a vida do que os que não tinham parentes militares e os universitários.

Além da influência do pai, a segurança econômica, as amizades no colégio militar, a vocação, o gosto pelas atividades, a admiração pela carreira militar e a estabilidade financeira foram citados como um conjunto de fatores para a decisão de prestar o concurso. Na pesquisa de Rosa (2006), já referida, a vocação foi assinalada por 54\% dos jovens, seguida pela estabilidade (15\%). Esses fatores corroboram a afirmação de Bucher-Malusckhe (2008): o sujeito é fruto de todo o contexto em que está inserido. As falas que seguem exemplificam 48 o que foi dito:
Eu tinha amigos que a maioria era filhos de militar também...e convivia muito nesse meio... (cadete n 4).

Hoje em dia eu diria que a segurança econômica é um fator... é... você poder trabalhar mais tranquilo com relação à situação econômica... (cadete no 8).

Fui motivado pelo fato de estar me sentindo bem aqui... no meio militar... de gostar da atividade... de gostar de colocar a mochila e andar... e ir pro meio do mato... (cadete no 12).

Essa última fala remete ao que foi encontrado na pesquisa de Rosa (2006), que constatou o predomínio, nos cadetes, do fator denominado "mudança", que significa o gosto pelo novo e pelo diferente, bem como o desejo de explorar novas paisagens, o qual faz parte do Inventário Fatorial de Personalidade por ele utilizado.

\section{Dificuldades encontradas}

Nesse tema, verificou-se o quanto os cadetes lidam com frustrações e aprendem a enfrentar as responsabilidades desde o primeiro ano de ingresso na academia. Para Castro (2004) e Takahashi (2002), o período de adaptação é usado pelos oficiais que comandam os exercícios e os treinamentos para pressionar, ao extremo, os aspirantes, nos aspectos físicos e psicológicos. 0 objetivo é selecionar aqueles que são capazes de se adaptar à vida na academia com exercícios pesados e exaustivos.

As maiores dificuldades relatadas pela maioria foram o afastamento, a saudade da família, assim como a perda da proteção dos pais. Segundo os entrevistados, a distância física e a dependência emocional são limites a serem superados, principalmente nos primeiros anos. Para alguns deles, o saber lidar com esses desafios é condição fundamental para crescer na vida profissional, e quanto mais rápido o cadete se desvincula da dependência da família, mais rápido se adapta à vida militar. "A maior dificuldade seria essa parte de ficar longe de casa, de não poder tá ali sempre com a família. Se você consegue levar exatamente isso, não vai ter dificuldade" (cadete no 13).

Foi possível perceber que o requisito para cumprir a delegação, como refere Stierlin (citado por Miermont, 1994), e assim manter o compromisso, é o afastamento da família e a dedicação às atividades militares. Parece existir uma espécie de pacto em que 
estão implícitos valores e normas que devem permanecer e em que todos os membros (pais, filhos e familiares) estão implicados. Outro aspecto também observado diz respeito às lealdades, definidas por Boszormenyi-Nagy e Spark (2003), em que o filho prova sua lealdade ao corresponder à missão que Ihe foi encomendada, apesar dos obstáculos. Dessa forma, pode-se dizer que o "caráter sagrado" (Krom, 2000, p.16), revelado nas entrevistas, sobre o seguir a carreira de oficial combatente apareceu fortemente, reforçado pelos vínculos estabelecidos entre os membros da família. Nenhum dos cadetes relatou queixas, reclamações ou qualquer tipo de incentivo, por parte dos familiares, para refletir sobre o curso ou mesmo abandonar a carreira militar. $O$ "mandato" parece servir para manter as alianças (Krom, 2000, p.18). Além disso, a própria nomenclatura utilizada no quartel diante das atividades do militar - "missão" - reforça a semelhança com os aspectos teóricos citados por esses autores.

Ainda foram citadas outras dificuldades: o sistema de internato, o isolamento e a falta de liberdade, o ritmo das atividades e a responsabilidade precoce. Como fora referido por Castro (2004), a infinidade de detalhes e de condutas a serem seguidas constitui dificuldades para os cadetes.

Osistema de internato éalgo bastante difícil, a liberdade é meio complicada... (cadete no 3).

A dificuldade na academia é a rotina. Porque a rotina é muito pesada... massacra muito, fica um ambiente repetitivo... (cadete no 16).

No início vocêacha que é muita responsabilidade... você tem muita coisa que precisa aprender... a fazer coisas sozinho que normalmente você não faz quando está dentro de casa... (cadete no 19).

\section{Ganhos obtidos com a dedicação à carreira militar}

Os entrevistados enfatizaram ganhos pessoais e profissionais como forma de retorno pela dedicação à vida militar. Foram referidos: amadurecimento, responsabilidade, independência dos pais, vida mais regrada e organização. Também foram citados ganhos de natureza profissional: reconhecimento, recompensa e melhor classificação no curso. Tudo isso corrobora as afirmações de Teachman, Call e Segal (1993), que elencaram alguns dos ganhos obtidos por quem segue a carreira militar: treinamentos e aperfeiçoamento educacional; promoções e possibilidade de emprego estável, especialmente em tempo de crise econômica. Além disso, o militar se aposenta em meados de sua vida, tendo a oportunidade de se dedicar a uma segunda carreira. Além dos ganhos evidentes que foram elencados por eles, pode-se pensar também nos ganhos implícitos por estarem cumprindo a missão que lhes foi encomendada pelas gerações precedentes.

\begin{abstract}
Acho que os ganhos financeiros não são grandes, mas não se passa fome. Mas a partemoral a genteleva a ferro efogo. Emesmo sem querer, os pais passam isso para os filhos (cadete no 3).

A dedicação na academia ela tem um fatorqueépositivo que você percebe quase que diretamente a resposta à sua dedicação... no caso, a sua classificação e das vantagens que você recebe mediante isso... (cadete no 5).

Ah! Você começa a ser independente ali. No caso... começa a não ficar mais dependente de ninguém. Você sai cedo de casa e a partir daí você tá tocando tua vida, nãoé? (cadete no 11).
\end{abstract}

\section{Características essenciais do militar}

Nessa temática, os entrevistados citaram uma diversidade de características que são fundamentais para seguir a carreira militar. Foram elas: saber se desligar da família, ser organizado, ter disciplina, saber seguir regras, liderança, ter valores morais, capacidade de adaptar, saber cumprir ordens, ter vocação e vontade de ser oficial.

Todas essas qualidades foram enfatizadas como algo que pode ser identificado e desenvolvido durante o curso, pois, segundo os participantes, não há como prever, no início, quem irá desistir ou não irá se adaptar ao sistema, embora todos acreditem que o cadete que resolve trancar o curso não tenha ou não desenvolveu essas características. É como se a academia fosse o local de se testar todos esses requisitos e, depois de concluída essa etapa desafiadora, os aprovados comprovassem a capacidade de seguir carreira militar. Desse modo, seriam legítimos portadores dessas qualidades e, consequentemente, dignos dessa identidade.

Na pesquisa realizada por Rosa (2006), que utilizou como um dos instrumentos o Inventário Fatorial de 
Personalidade, os cadetes apresentaram diferenças significativas nos fatores mudança (gosto pelo novo e pelo diferente, explorar novas paisagens) e autonomia (fazer as coisas do seu próprio jeito, sem a tutela dos outros), em relação aos jovens universitários.

Outro aspecto evidenciado nas entrevistas foi o que Oliveira (2004) pontuou sobre o conceito de masculinidade. Esse autor enfatiza o modelo de masculino embasado em posturas de firmeza, autocontrole e sentimentos de nacionalismo. Essa concepção de masculinidade esteve implicitamente relatada pelos cadetes, na medida em que o militar deveria ser capaz de suportar as frustrações e os limites da dedicação à sua vida profissional. Eles acreditam que, sem essa capacidade, o jovem deve abandonar a carreira militar e partir para outros projetos profissionais. Porém, fica o questionamento: como fica esse jovem que não cumpriu o mandato? O que poderia estar implícito na sua desistência? Levanta-se a possibilidade de que os mitos individuais desse jovem não se encaixem nos mitos familiares ou que a missão que the foi confiada seja muito exigente para que ele a realize (Krom, 2000).

Têm umas qualidades que são pré-requisitos porque se não tiver... se for pra AMAN não vai ficar... o cara tem que saber se desligar da família... e os pais têm que deixar ele ir também... Eu acho que cada um tem sua personalidade... tem suas características... e a pessoa acaba encaixando a personalidade dela de modo diferente nessa profissão militar... (cadete no 3 ).

Eu acho que, para entrar, claro que tem um mínimo de pendor. Tem que aceitar o modo de vida que ele tá escolhendo... mas acho que justamente pra isso serve a formação, não é? A academia e um ano na ESPCEX... justamente pra moldar as pessoas à vida militar... acho que ninguém entra com o perfil ideal... (cadete no 13).

\section{$n$
0
$\vdots$
3
0
$\frac{1}{5}$
3
$\infty$
0
3
3
$\vdots$
0
0
$\frac{0}{5}$}

\section{Papel da família}

A família militar oferece um contexto único que não é experienciado por civis, pois as demandas sobre o pai são bastante específicas e exigentes (Eaton \& Fees, 2002). Durante o desenvolvimento dos filhos, em geral, os pais são bastante presentes, pois o expediente do pai começa cedo e termina cedo, além do fato de que a mãe, na maioria das vezes, abdica de uma carreira 50 profissional para se dedicar à família (Rosa, 2006). A família também se faz presente nas solenidades e comemorações, e devido às frequentes mudanças, tende a ser coesa e unida. Segundo Adão (2010), por conta dos constantes deslocamentos, que impedem os laços de solidariedade mais duradouros nos locais onde residem, as famílias buscam apoio nas outras famílias militares que vivem a mesma situação. Disso resultam o apego e o zelo pelos valores e princípios da instituição, que incentivam a integração dos membros nessa grande família. Constata-se, assim, a manutenção dos mitos da autoridade e da união (Krom, 2000).

Observou-se que todos os entrevistados falaram sobre a importância da família para o sucesso na carreira do militar. A família de origem e a família construída, após a formação do oficial, devem funcionar como fonte de apoio e sustentação. A compreensão e a confiança no pai, diante das exigências da carreira, são qualidades que, segundo os cadetes, não podem faltar na família do militar. Ao mesmo tempo em que ela assume uma função de proteção, deve permitir e entender seu afastamento para o crescimento profissional. Esses resultados podem ser confrontados com o "conjunto de características típicas da vida militar" (site oficial do exército), que adverte que a família sofrerá consequências da dedicação à carreira e, por isso, deverá ser compreensiva e estar ciente dessa possibilidade. Para Stafford e Grady (2003), são fatores de risco para a carreira do militar quando a família apresenta pouca capacidade de adaptação, conflitos familiares, disfunções e pobre comunicação.

A participação da família é fundamental. Por exemplo, meu tio foi servir numa cidade que não tinha estrada, escola, nada, porque eleéde engenharia. A esposa deleé que foi professora das minhas primas. O militar precisa muito do apoio da família (cadete no 1).

Ah! A família tem que entender que quando o exército precisar dele, ele vai chamar. Ele não vai estar 24 horas junto com a família. Às vezes o exército exige mais do que o necessário... e a família fica um pouco desamparada ali... mas... isso já é desde que o militar entra na carreira. No caso, ele tá sabendo disso e vai ter que preparar a família dele também... (cadete n 5).

\section{Expectativas para o futuro}

As preocupações, inicialmente, estão voltadas para a vivência na academia, tais como: classificação, 
capacidade de praticar com segurança as habilidades desenvolvidas no curso, escolha do local onde irá servir depois de formado, melhorar o desempenho nos estudos e adquirir cada vez mais conhecimento. Em relação à carreira militar, foram relatadas: transferências (mobilidade geográfica prevista a cada três anos, em média) e dificuldades para formar família; valorização da sociedade em relação à importância da profissão; reconhecimento das questões salariais e estabilidade no ambiente de trabalho.

A gente se preocupa muito com a parte financeira. Também é uma carreira muito bonita... a gente vê quando a gente tá andando, a gentevêassim na cidade, o que faz a necessidade do exército para a sociedade, porém a gentefica com medo é... destereconhecimento não ocorrer por parte da população, nãoé? (cadete n०3).

Minhas preocupações, bom... aqui na AMAN é dar uma melhorada na classificação... (cadete no 15).

Geralmente as preocupações... é... formar família. Constituirfamília, não é? Porque hoje pelo fato da mulher querer estar sempre no mercado de trabalho também, isso pode ser uma coisa que gere problema. A mulher, por exemplo, quer trabalhar e muitas vezes eu vou estar sendo transferido e tal... isso pode trazer problemas... (cadete n०20).

Essa última preocupação tem como base as constantes transferências do militar e a dificuldade de conciliá-las à carreira da futura esposa. Segundo Stafford e Grady (2003), a família militar move-se duas a três vezes mais frequentemente que a dos civis, o que, certamente, acarreta a necessidade de muito diálogo e negociação por parte do casal.

\section{Considerações Finais}

Pode-se concluir que esta pesquisa evidenciou a influência do pai como decisiva na escolha do filho pela carreira militar. Essa influência se fez presente antes, durante e depois do ingresso do filho na carreira. Além disso, a família, como um todo, propiciou o apoio necessário para que o jovem alcançasse esse objetivo. Retomando os objetivos específicos, no que se refere aos motivos que favoreceram a escolha, constatou-se que, além da influência paterna, a admiração pela carreira e a intimidade com as normas e procedimentos inerentes a ela também ajudaram. Os sentimentos expressos, em geral, foram de orgulho, satisfação e honra, em que pese o reconhecimento das perdas e sacrifícios que a carreira exige. Os fatores facilitadores foram o apoio da família e as características pessoais, como capacidade de adaptação, organização, disciplina, possuir valores morais e saber cumprir ordens. Entretanto, os fatores críticos foram o afastamento de casa e a consequente perda da proteção paterna, o isolamento, a falta de liberdade devido ao regime de internato, o ritmo das atividades e a responsabilidade precoce. Finalmente, acerca das expectativas, percebeu-se que eles estudam para melhorar o desempenho e obter melhores colocações, uma vez que esses resultados vão interferir na escolha da região em que irão servir durante toda a carreira profissional, assim como no período de promoção e indicação para cursos e missões fora do país, dentre outros. Além disso, foi percebido o desejo de formar uma família, mais tarde, embora se preocupem com os deslocamentos constantes, o que pode dificultar a carreira da futura esposa.

Tendo em vista ser esta uma pesquisa de natureza qualitativa, sabe-se não ser possível generalizar os achados. Sugere-se a realização de novas investigações que possam complementar o que foi encontrado e que poderiam ser dirigidas por algumas perguntas norteadoras, tais como: Como acontece o processo de escolha profissional dos cadetes filhos de civis? Será que eles apresentam maiores dificuldades de adaptação à academia? Qual a influência sofrida, quanto ao interesse para realizar o concurso, entre os filhos de civis? Será que a dinâmica familiar dos cadetes filhos dos civis apresenta características que diferem da família militar? O que diferencia os filhos de pais militares, uma vez que uns seguem a mesma carreira e outros não? Como está hoje essa família diante de tantas mudanças sociais, como é caso dos papéis de gênero? Também se propõe a realização de pesquisas em que os participantes sejam os pais militares, as mães ou as esposas.

Diante da carência de estudos e de bibliografia sobre o tema na realidade brasileira e da necessidade de conhecimentos acerca da carreira militar e suas ressonâncias na vida familiar, espera-se que esta pesquisa possa dar visibilidade às especificidades da escolha por 
essa carreira. Espera-se que ela forneça subsídios aos profissionais que lidam com os militares oficiais do exército e suas famílias, especialmente na orientação aos jovens que pretendem seguir essa profissão, bem como estimule novos estudos na área.

\section{Referências}

Adão, M. C. O. (2010). Aspectos da adesão feminina aos valores militares: o casamento e a família militar. Revista História, 29 (2), 116-134.

Andolfi, M., \& Ângelo, C. (1988). Tempo emito em psicoterapia familiar. Porto Alegre: Artes Médicas.

Boszormenyi-Nagy, I., \& Spark, G. M. (2003). Lealtades invisibles. Buenos Aires: Amorrortu.

Brasil. Ministério da Defesa. Exército Brasileiro (1980). Estatuto dos militares. Recuperado em outubro 9, 2006, disponível em <http://www.ensino.eb.br>.

Brasil. Ministério da Defesa. Exército Brasileiro (1998). Educação e formação militar. Regulamento da AMAN - R70. Recuperado em outubro 9, 2006, disponível em <http:// www.ensino.eb.br>.

Bucher-Maluschke, J. S. N. F. (2008). Do transgeracional na perspectiva sistêmica à transmissão psíquica entre as gerações na perspectiva da psicanálise. In M. A. Penso \& L. F. Costa (Orgs.), A transmissão geracional em diferentes contextos, da pesquisa à intervenção (pp.76-96). São Paulo: Summus.

Castro, C. (2004.). Oespírito militar:um antropólogo na caserna. Rio de Janeiro: Jorge Zahar.

Cia, F., \& Barbam, E. J. (2008). Trabalho noturno e o novo papel paterno: uma interface difícil. Estudos de Psicologia (Campinas), 25 (2), 211-222. doi: 10.1590/S0103-166X2 008000200003.

Corneau, G. (1997). Pai ausente filho carente: o que aconteceu com os homens? São Paulo: Brasiliense.

Costa, J. F. (1994). Ordem médica e norma familiar (4ª ed.). São Paulo: Graal.
Eaton, M., \& Fees, B. S. (2002). Perceptions of influence on child's competence among fathers in the military context. Psychological Reports, 91 (3), 703-710.

Falcke, D., \& Wagner, A. (2005). A dinâmica familiar e o fenômeno da transgeracionalidade: definição de conceitos. In A. Wagner (Coord.), Como se perpetua a família? (pp.25-45). Porto Alegre: PUCRS.

Jablonsky, B. (1999). Identidade masculina e o exercício da paternidade: de onde viemos e para onde vamos. In T. Féres-Carneiro (Org.), Casal e família: entre a tradição e a transformação (pp.55-67). Rio de Janeiro: Nau.

Krom, M. (2000). Família e mitos: prevenção e terapia: resgatando histórias. São Paulo: Summus.

Miermont, J. (1994). Dicionário de terapias familiares, teoria e prática. Porto Alegre: Artes Médicas.

Minayo, M. C. S. (2004). O desafio do conhecimento: pesquisa qualitativa em saúde (8a ed.). São Paulo: Hucitec.

Oliveira, P. P. (2004). A construção social da masculinidade. Belo Horizonte: IUPERJ.

Prieur, B. (1999). Que recebemos da família? In B. Prieur (Coord.), As heranças familiares (pp.19-25). Lisboa: Climepsi.

Rosa, F. H. (2006). Satisfação de vida, estilos parentais e personalidade em militares e universitários. Tese de doutorado não-publicada, Universidade Federal do Rio Grande do Sul, Porto Alegre.

Stafford, E. M., \& Grady, B. A. (2003). Military family support. Pediatric Annals, 32 (2), 110-115.

Takahashi, E. E. (2002). Homens e mulheres em campo: um estudo sobre a formação da identidade militar. Tese de doutorado não-publicada, Universidade Estadual de Campinas.

Teachman, J. D., Call, V. R. A., \& Segal, M. M. (1993). Family, work and school influences on the decision to enter the military. Journal of Family Issues, 14 (2), 291-313.

Recebido em: 3/4/2009

Versão final reapresentada em: 16/6/2011

Aprovado em: 6/9/2011 